\title{
Dysfunctional regulation of ocular blood flow: A risk factor for glaucoma?
}

\author{
Danny Moore \\ Alon Harris \\ Darrell WuDunn \\ Nisha Kheradiya \\ Brent Siesky' \\ Department of Ophthalmology, \\ Indiana University School of Medicine, \\ Indianapolis, IN, USA
}

\begin{abstract}
Primary open angle glaucoma (OAG) is a multifactorial optic neuropathy characterized by progressive retinal ganglion cell death and associated visual field loss. OAG is an emerging disease with increasing costs and negative outcomes, yet its fundamental pathophysiology remains largely undetermined. A major treatable risk factor for glaucoma is elevated intraocular pressure (IOP). Despite the medical lowering of IOP, however, some glaucoma patients continue to experience disease progression and subsequent irreversible vision loss. The scientific community continues to accrue evidence suggesting that alterations in ocular blood flow play a prominent role in OAG disease processes. This article develops the thesis that dysfunctional regulation of ocular blood flow may contribute to glaucomatous optic neuropathy. Evidence suggests that impaired vascular autoregulation renders the optic nerve head susceptible to decreases in ocular perfusion pressure, increases in IOP, and/or increased local metabolic demands. Ischemic damage, which likely contributes to further impairment in autoregulation, results in changes to the optic nerve head consistent with glaucoma. Included in this review are discussions of conditions thought to contribute to vascular regulatory dysfunction in OAG, including atherosclerosis, vasospasm, and endothelial dysfunction.
\end{abstract}

Keywords: glaucoma, autoregulation, blood flow, atherosclerosis, vasospasm, endothelial dysfunction

\section{Introduction}

Primary open angle glaucoma $(\mathrm{OAG})$ is a multifactorial optic neuropathy characterized by progressive retinal ganglion cell death and associated visual field loss. Glaucoma is the second leading cause of blindness worldwide (Leske 2007), yet after years of extensive research the exact cause of glaucomatous optic neuropathy remains elusive. A recent estimate suggests that roughly 80 million people will be diagnosed with glaucoma by 2010, with 4.5 million of those suffering from bilateral blindness (Quigley and Broman 2006). Although elevated intraocular pressure (IOP) currently remains the focus of therapy, some glaucoma patients continue to experience disease progression despite lowering of IOP. The Early Manifest Glaucoma Trial (EMGT) showed that OAG disease progression rate in the treatment group was $45 \%$ as compared with $62 \%$ in the nontreated control group (Heijl et al 2002). In the Collaborative Initial Glaucoma Treatment Study (CIGTS), substantial visual field loss occurred in 10\%-13.5\% of participants during 5 years of follow up (Lichter et al 2001). Although IOP is still the only treatable OAG risk factor, it is clear that glaucoma is a complex disease that cannot be prevented or cured by IOP reducing therapies in all patients.

Other glaucoma risk factors that may be responsible for disease progression despite lowering of IOP include vascular risk factors, genetics, and other systemic conditions (Leske 2007). Vascular related OAG risk factors have been found in prospective, retrospective, and large population-based studies throughout the world. While not a new concept (von Graefe 1857; Hayreh et al 1970; Hayreh 2001; Flammer et al 2001), 
disturbed ocular blood flow has emerged as an increasingly prevalent glaucoma risk factor in large population-based trials. Leske and colleagues (2007) recently presented new predictors of OAG disease progression in the EMGT trial including lower systolic perfusion pressure, lower systolic blood pressure, and cardiovascular disease history. In the Rotterdam eye study, patients with an ocular perfusion pressure lower than $50 \mathrm{mmHg}$ had a four times greater risk of developing OAG than those with a perfusion pressure of $80 \mathrm{mmHg}$ (Hulsman et al 2007). The Egna-Neumarkt study found positive correlations between systemic blood pressure and both the diagnosis of OAG and elevated IOP (Bonomi et al 2000). These large scale trials compliment various data from smaller prospective trials which have found aging, systemic blood pressure, nocturnal hypotension, ocular perfusion pressure, migraine, disk hemorrhage, diabetes, and directly assessed reductions of ocular blood flow to be related to OAG. It is currently unclear whether ischemia is secondary to increased IOP through faulty autoregulation of ocular blood flow or if a primary vascular component promotes damage to the optic nerve and retinal ganglion cells in certain OAG patients.

Recent studies have also suggested that perfusion instability, rather than a progressive decline in ocular blood flow, may contribute to OAG. It is well established that circadian rhythms play an important role in maintaining homeostasis in the human body. In that capacity, OAG progression is not necessarily related to the overall level of blood pressure, but an abnormal vascular reaction to a reduction in blood pressure or increase in IOP during nonwaking hours (Werne et al 2008). It has been known for over four decades that IOP varies throughout the day, but not until recently has it been shown that other vascular risk factors such as systemic blood pressure (O’Brien 1991), ocular perfusion pressure (Liu et al 2003), and ocular blood flow (Osusky et al 2000) also follow circadian patterns. Ocular blood flow deficits may therefore represent either a primary insult or are secondary to vascular regulatory dysfunction during diurnal fluctuations in vascular risk factors in certain OAG patients (Grieshaber and Flammer 2005).

\section{Blood flow autoregulation in glaucoma}

Autoregulation of blood flow is described as the intrinsic capacity of an organ to maintain its blood flow despite changes in local vascular parameters (Haggendal et al 1969). Within the eye, autoregulation is defined as local vascular constriction or dilation causing vascular resistance to reciprocally increase or decrease, thereby maintaining a constant nutrient supply in response to perfusion pressure changes (Harris et al 1998). Challenges to normal ocular blood flow include increased IOP, fluctuating blood pressure, a resultant decrease in ocular perfusion pressure, and/or a rise in local tissue metabolic demands. Failure of stable blood flow regulation may lead to ischemic damage of the optic nerve and/or retinal ganglion cells, which likely contributes to further impairment in vascular regulation. A cascade of events may occur, which then leads to retinal ganglion cell death and structural changes of the optic nerve head (ONH) (Flammer et al 2001) consistent with OAG pathophysiology (Figure 1).

Various underlying medical conditions have been proposed which may contribute to ocular vascular regulatory dysfunction including atherosclerosis, vasospasm, and endothelial dysfunction. This review highlights these and other factors as they relate to glaucomatous optic neuropathy and discusses potential implications in our understanding of OAG disease pathophysiology and management.

\section{Physiology of the optic nerve head blood flow autoregulation}

The optic nerve is a continuation of the central nervous system and shares several physiologic similarities with the brain, including blood flow autoregulation (Flammer and Orgul 1998). Despite extensive research, the precise microvascular anatomy and blood flow regulation of the $\mathrm{ONH}$ remains difficult to ascertain (Harris et al 2003). Several mechanisms involved in the vascular regulation of ocular blood flow that have been demonstrated include: metabolic, myogenic, neurogenic, humoral, and endothelial-mediated factors.

Autoregulation of the cerebral circulation has been shown to depend largely on local blood gas perturbations (Haggendal et al 1969). Similarly, as ONH blood flow decreases, the local metabolic vascular response is primarily oxygen-dependent (Kontos et al 1978). Hyperoxia and hypocapnia mediate arteriolar constriction and a subsequent decrease in ONH blood flow, while hypoxia and hypercapnia result in the opposite response (Flammer and Orgul 1998). Additionally, the concentrations of $\mathrm{K}^{+}, \mathrm{H}^{+}$, adenosine, and intercellular osmolarity are known to influence local vascular tone (Orgul et al 1995a).

Myogenic autoregulation involves arteriolar tone changes through smooth muscle cell to cell signal propagation (Johnson 1986). Specifically, transmural pressure sensitive arteriole pacemaker cells initiate the response and although the exact mechanism has not been defined, extracellular calcium concentrations and endothelial factors appear to 


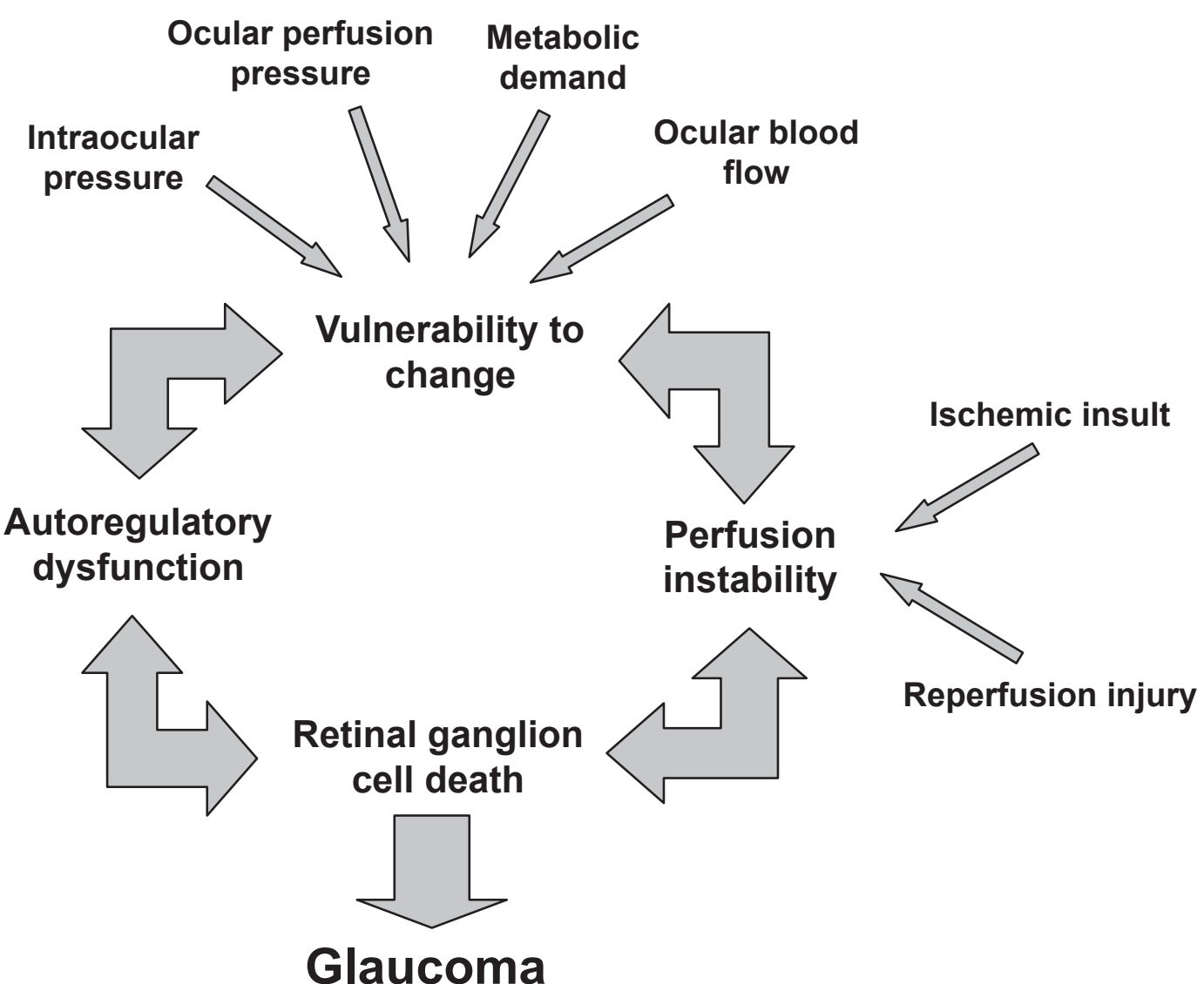

Figure I A conceptual representation of the contribution of autoregulatory dysfunction to glaucomatous damage of the optic nerve head.

contribute (Davies and Tripathi 1993). While myogenic autoregulation contributes to a great extent in several organs, most notably the colonic vasculature (Andersson 1984), its role in ocular tissue is still under investigation.

The autonomic nervous system orchestrates a coordinated response to changes in systemic physiology. In the coronary circulation, for example, intrinsic cardiac and extracardiac autonomic neurons influence cardiac output and coronary blood flow, often irrespective of local stimuli (Kresh and Armour 1997). In ocular tissue, the autonomic nervous system contributes extensively to the retrobulbar and choroidal circulatory system, but the retinal and $\mathrm{ONH}$ vasculature lack direct innervation (Funk 1997). Hence, sympathetic stimulation provides only indirect influence on $\mathrm{OHN}$ perfusion as neurogenic contribution to the vascular response is minimal (Harris et al 2003).

In a prototypical vascular bed, vasoactive hormones in the circulating blood act directly on endothelial, pericyte, and smooth muscle cells. The ONH, however, is exceptional in that it contains 1) a blood - brain barrier preventing smooth muscle and pericyte contact with humoral factors and 2) a scleral flange also acting as a barrier to prevent humoral diffusion from the choroid to the ONH (Flammer and Orgul 1998). Hormones believed to exert an autoregulatory effect on the $\mathrm{ONH}$ by overcoming these barriers include circulating catecholamines (Yu et al 1994), vasopressin, natriuretic peptides, and the renin - angiotensin system (Jossi and Anderson 1983).

The vascular endothelium directly regulates permeability, but also indirectly influences blood vessel diameter, coagulation parameters, cellular proliferation, and the inflammatory cascade amongst other pathways through the release of vasoactive susbstances (Behrendt and Ganz 2002). Endothelial mediators are increasingly reported factors in the regulation of ONH blood flow. Studies have demonstrated a basal formation of nitric oxide in the ocular endothelium that leads to active dilatation of the vasculature as well as a dose-dependent response relationship between endothelin-1 and blood flow to the anterior optic nerve, as discussed in detail later (Orgul et al 1999).

\section{Atherosclerosis}

Atherosclerosis is a chronic, progressive disease affecting many vascular beds including the ocular circulation (Davies 
1990). It results from the deposition of lipids, inflammatory cells, and connective tissue within arterial walls, leading to plaque formation and intimal thickening. Over time this results in obstruction to flow, compromised perfusion, and tissue ischemia (Davies et al 2004; de Voogd et al 2006). Recent research on the topic of atherosclerosis has focused on molecular and cellular mechanisms and led to a shift in the paradigm of disease pathophysiology (Davies et al 2004). Studies have shown endothelial cell dysfunction to be the first detectable change in atherosclerotic vessels (Behrendt and Ganz 2002). This is supported by the observation that risk factors such as aging, smoking, hypertension, elevated low-density lipoprotein (LDL) levels, diabetes, and ischemia have been shown to alter endothelial function (Luscher et al 1993). Both the barrier and secretory function of endothelial cells are perturbed in atherosclerosis, aiding in plaque formation. This also manifests as abnormal vasoreactivity in affected vessels, suggesting a predisposition to ischemic insult (Bogaty et al 1994).

The current literature collectively demonstrates various mechanisms leading to autoregulatory dysfunction in atherosclerotic vessels. However, a corollary correlation between atherosclerosis and OAG has yet to be identified. The prospective Rotterdam eye study found neither atherosclerosis nor serum C-reactive protein (a marker of inflammation associated with atherosclerosis) to be important risk factors for the development of OAG (de Voogd et al 2006). This is consistent with previous studies which were unable to find a significant relationship between atherosclerosis and OAG (Levene 1980; Hayreh 1993; Gasser 1998). Conversely, Hayreh (1999) noted that serotonin, a biomarker released during platelet aggregation on an atherosclerotic plaque, produced vasospasm of the central retinal and short posterior ciliary arteries in atherosclerotic monkeys. While lacking a control group and not performed in human subjects, Hayreh cites previous reports suggesting improvement of serotonin induced vasoconstriction after abstaining from an atherogenic diet for several months. Further, a recent study found over-expression of a specific subset of the phospholipase A2 enzyme family, a marker for atherosclerosis, in the ocular tissue of OAG patients (Ronkko et al 2007). However, this result may point more to the role of oxidative stress than atherosclerosis in OAG disease pathogenesis.

It is important to note that noninvasive measurements of atherosclerosis are of limited utility. The methods used in previous studies included echography or radiography of the carotid arteries to quantify intimal thickness, abdominal imaging to measure calcification in the aorta and anklebrachial index (de Voogd et al 2006). These techniques are intended to provide in vivo quantification of systemic atherosclerosis, but measure only isolated vascular beds. Further, no study directly visualized the ocular circulation in humans, indicating a need for additional studies to accurately identify localized atherosclerosis and resulting changes in the vasculature of OAG patients.

Since atherosclerosis has a known association with other vascular risk factors such as aging, cerebrovascular and cardiovascular disease, several studies have attempted to discern a correlation between these factors and glaucoma. A recent report from the EMGT indicated cardiovascular disease history is a newly defined predictor of glaucomatous disease progression (Leske et al 2007). As a systemic process, atherosclerosis plays a causative role in such pathology as myocardial infarction and cerebral vascular accidents. Several studies have reported an increased incidence of silent myocardial ischemia in glaucoma patients (Kaiser et al 1993; Waldmann et al 1996), while multiple reports link cerebral ischemia and infarct with glaucoma (Stroman et al 1995; Ong et al 1995; Tutaj et al 2004). Further, the incidence of OAG, atherosclerosis, and ocular ischemia are known to increase with age (Harris et al 2000). With advancing age, there is a decrease in the relative capillary blood flow, velocity, and volume within the neuroretinal rim and lamina cribrosa of the ONH (Boehm et al 2005). Although multiple factors likely contribute to this process, it has been determined that retinal arteriolar and venular diameters narrow during normal aging due to age-associated vascular rigidity and atherosclerosis (Leung et al 2003). This prevents the elderly population from having the same capacity to alter vessel diameter and thus blood flow as a function of autoregulation (Wong et al 2003). This may help explain the observation that endothelial function of the retinal vasculature improves with angiotension AT1 receptor blockade in young patients, but shows no response in older individuals (Delles and Schmieder 2004; Oehmer et al 2006).

In summary, atherosclerosis has been demonstrated to cause autoregulatory dysfunction in multiple vascular beds resulting in significant vascular disease pathologies. Although a relationship between certain atherosclerotic risk factors and OAG has been reported, the direct influence of atherosclerosis on the progression of glaucoma is undetermined. More research is required to understand how atherosclerosis, cardiovascular disease, age, and blood flow autoregulation are inter-related in OAG disease pathophysiology.

\section{Vasospasm}

Vasospasm is characterized as a sharp, exaggerated, and often persistent contraction of a blood vessel, resulting in 
a reduction in luminal diameter and respective blood flow (Mchedlishvili 1981). This vasoconstriction or insufficient dilatation of the microcirculation may lead to inadequate blood flow to the surrounding tissue and consequent ischemia. Simultaneous arterial or venous dilatations in neighboring vascular beds may be a by-product of vascular dysregulation in vasospastic individuals (Flammer 1998). Certain organs, such as the heart, brain, and eye produce clinically apparent spasms more regularly than other organ systems.

Vasospasm has been associated as a secondary finding in multiple disease states including multiple sclerosis, lupus erythematosus, antiphospholipid syndrome, rheumatoid arthritis, giant cell arthritis, Behcet's disease, Crohn's disease, Buerger's disease, Raynaud's disease, prinzmetal's angina, preeclampsia, and AIDS (Gasser 1991; Flammer et al 2001). However, a primary vasospastic syndrome has also been discovered wherein patients without an underlying disease develop vasospasm in response to stimuli such as cold or emotional stress (Gasser et al 1990). This disorder is of particular interest since the most commonly reported organ involving vasospasm is the eye (Gasser 1991). This syndrome is found more frequently in women than men (Flammer and Prunte 1991), which possibly correlates with the observation that normal tension glaucoma (NTG) is twice as common in women. Furthermore, the female gender is considered an independent risk factor for visual field loss progression in NTG (Orgul et al 1994; Drance et al 2001). The increased susceptibility in females may be due to falling estrogen levels, which are known to have a vasoprotective effect and are reduced post-menopause (Siesky et al 2008). Similarly, vasospasm is also observed more commonly in Japanese than Caucasian patients and correspondingly, NTG is found more commonly in Japan than most other countries (Beltrame et al 1999; Flammer et al 2001). These and various other studies suggest that vasospasm may exemplify a specific mechanism by which glaucomatous changes can occur (Kaiser et al 1993a; Nicolela et al 1996; Gasser 1998; Anderson et al 1999; Flammer et al 2001). Vasospasm can create an environment of blood flow dysregulation which increases the vulnerability of the $\mathrm{ONH}$ to vascular challenges, leading to perfusion instability, ischemic changes, axonal loss, and changes of the $\mathrm{ONH}$.

The most prevalent clinical signs and symptoms of vasospasm are cold hands and feet, low blood pressure, and migraine (Gasser 1989, 1998; Gasser et al 1990; Orgul et al 1995b; Flammer et al 2001). A systematic diagnosis of vasospasm syndrome has yet to be defined, but it has been suggested that finger or nail blood flow response to cold provocation can be diagnostic (Drance et al 1998; Gasser and Flammer 1991). It is important to note that patients with glaucoma who have been shown to have evidence of vasospasm were more likely to demonstrate worsening of visual fields following cooling than nonvasospastic patients (Nicolela et al 2003). This suggests that vasospasm may manifest itself in clinically relevant glaucomatous deterioration in certain individuals. Migraine, often characterized as a vasospastic disorder, is more commonly found in females and has a well documented association with NTG (Cursiefen et al 2000). It has been demonstrated as a risk factor for the progression of visual field loss, suggesting a common underlying vascular pathology for both conditions (McKendrick et al 2000). Also frequently associated with vasospasm, low blood pressure is a reported risk factor for glaucoma, but if systemic hypotension is secondary to vasospasm or an unrelated phenomenon remains uncertain (Kaiser et al 1993b; Gass et al 1997; Gasser 1998; Pache et al 2003). It has been shown that blood pressure variations away from normal physiologic nocturnal dips are correlated with vasospasm, OAG, and NTG (Werne et al 2008). The failure of ocular blood flow to remain constant during physiological challenges may manifest itself as ocular vasospasm or represent primary vascular dysregulation during vasospastic episodes.

Vasospasm is a transient phenomenon that is potentially reversible, allowing the restoration of steady-state perfusion. Due to its time-dependent nature, baseline blood flow measurements may not demonstrate any abnormalities compared with controls (Gugleta et al 2003). Therefore, the use of a provocation test to unmask underlying vascular dysregulation has been proposed in ocular hemodynamic measurements (Gugleta et al 2005). Studies have been conducted to demonstrate this reversibility. Increased visual field deficits have been demonstrated after cold water provocation in vasospastic patients that decreased with the administration of calcium channel blockers or magnesium (Gasser et al 1990; Gasser and Flammer 1990; Gaspar et al 1995). Likewise, treatment with calcium channel blockers has been shown to improve retrobulbar hemodynamics in some patients with NTG (Harris et al 1997). In addition to calcium channel blockers, hyperoxia and elevated carbon dioxide $\left(\mathrm{CO}_{2}\right)$ breathing are sometimes utilized to assess vascular reactivity. While studies investigating the retinal circulatory response to blood gas perturbations report conflicting results (Gugleta et al 2003), reports consistently indicate $\mathrm{CO}_{2}$ inhalation provides a reversible improvement in visual field defects and a decrease in the resistive indices of orbital vessels (Wilson et al 1997; Niwa et al 2000). Specifically, Harris and colleagues (1994) 
showed that NTG patients had significantly lower ophthalmic artery blood flow velocities and higher vascular resistance than controls. The differences between NTG and controls were reversed during elevated $\mathrm{CO}_{2}$ breathing, suggesting the presence of a reversible vasospasm in the NTG cohort (Harris et al 1994). A study by Gugleta and colleagues (2005) found women with vasospasm demonstrated an inverse response pattern of choroidal and ONH blood gas perturbations compared with women without vasospasm. The authors suggest that vasospastic patients may have diminished autoregulatory capacity or increased responsiveness to $\mathrm{CO}_{2}$ in certain vascular beds. A differentiation of normal and abnormal blood flow regulation during blood gas perturbations and calcium channel blockers may demonstrate which persons are at greatest risk for vasospasm, impaired ocular blood flow and possibly OAG.

The current body of literature suggests that vasospasm may play a more significant role in OAG ONH damage than atherosclerosis. Although both conditions have been shown to contribute to systemic autoregulatory dysfunction, it is hypothesized that most patients with increased vascular resistance secondary to atherosclerotic change compensate with proficient autoregulation in small arterioles and capillaries (Flammer et al 1999). Intracranial vessels seem more resistant to the development of atherosclerosis in comparison to other vascular beds (Faraci and Heistadt 1998). While effects of atherosclerosis are readily apparent on fundoscopic exam, relying on these changes for measure of systemic and retinal disease may be of limited utility (Helvaci et al 2007). It is believed that perfusion fluctuates more dramatically in vasospastic patients, which can additionally lead to reperfusion damage (Schempp and Elstner 1998).

The concept of vasospasm-induced reperfusion injury is heavily emphasized in other fields of research including vascular and transplant surgery (Jokuszies et al 2006), neurology (Reid et al 1995), and cardiology (Laude et al 2004). During myocardial ischemia and infarction, for example, reperfusion is characterized by the overproduction of oxygen-derived free radicals that spurn an acute inflammatory response and tissue degradation. It has also been argued that reperfusion injury alters the endothelium architecture, allowing for such adverse conditions as vasospasm and atherosclerosis to develop more readily (Laude et al 2004).

In summary, vasospasm is associated with multiple disease states including OAG with NTG patients and women appearing to be the most at risk for vasopastic contributions to disease processes. Vasospasm may result in fluctuations in ocular perfusion, ischemia, and/or reperfusion injury to the ocular tissues. Importantly, vasospasm may be reversible (treatable). The capacity of diagnostic testing for OAG risk using blood gas perturbations should be further explored, especially in patients that demonstrate a vasospastic propensity.

\section{Endothelial dysfunction}

Endothelial dysfunction has been increasingly implicated in OAG disease pathophysiology. Disruption of the homeostatic factors maintaining physiologic vessel caliber may shift the balance toward an excess of vasoconstriction over vasodilation resulting in vasospasm (Delaney et al 2006). Similarly, atherosclerosis changes endothelial architecture and disrupts mechanisms contributing to endothelium-derived vascular relaxation (Faraci and Heistadt 1998). A causative and/or synergistic role involving atherosclerosis, vasospasm, and endothelial dysfunction may result in dysfunctional regulation of the ocular vasculature potentially contributing to OAG pathophysiology.

The vascular endothelium regulates the microcirculation through release of vasoactive factors, the most potent of which are the vasodilator nitric oxide (NO) and the vasoconstrictor endothelin-1 (ET-1) (Adams 2006). Additional endothelium-derived activating compounds include prostacyclins, acetylcholine, bradykinin, and histamine (Flammer and Orgul 1998; Adams 2006). In endothelial cells, NO synthase (NOS) catalyzes the conversion of L-arginine to NO and L-citrulline. NO released from endothelial cells directly stimulates the surrounding vascular smooth muscle to promote vasodilation (Toda and Nakanishi-Toda 2007). Systemic factors such as hyperlipidemia, atherosclerosis, and hyperglycemia impair endothelial NO signaling through oxidative stress damage (Napoli et al 2001). Plasma levels of asymmetric dimethylarginine, an endogenous inhibitor of NOS, are disproportionately elevated in hyperlipidemia, hyperhomocystinemia, atherosclerosis, coronary artery disease, hyperglycemia, and other disorders affected by endothelial dysfunction (Miyazaki et al 1999; Delaney et al 2006). Conversely, infusions of L-arginine, a precursor molecule to NO, limit injury from ischemia, and reperfusion-induced endothelial dysfunction (Pernow et al 2003).

It is known that NO activity contributes to ocular autoregulation and can protect the endothelium and nerve fiber layer against pathologic stressors implicated in glaucoma, ischemia, and diabetes (Toda and Nakanishi-Toda 2007). A recent report by Polak and colleagues (2007) presents the first in vivo evidence for altered ocular L-arginine/NO pathway in glaucoma patients. Polymorphisms in the 
endothelium specific NOS (eNOS) have been found in familial patients with glaucoma (Tunny et al 1998). A preliminary study by Wiggs and colleagues also suggests the presence of a polymorphism in the eNOS gene in patients with high and NTG that predisposes these patients to superior paracentral field loss (Delaney et al 2006). Decreased levels of cyclic GMP, an indicator of NO activity, have been demonstrated in the plasma and aqueous humor of glaucoma patients, with corresponding lower systolic and diastolic ophthalmic artery blood flow velocities of NTG patients (Laude et al 2004).

Opposing the vasodilation properties of NO is ET-1, the most important and potent vascular constricting factor. The peptide is synthesized by endothelial cells and either binds to the $\mathrm{ET}_{\mathrm{A}}$ receptor on smooth muscle cells to mediate vasoconstriction or binds to the $\mathrm{ET}_{\mathrm{B}}$ receptor on endothelial cells to mediate vasodilation via the autocrine release of NO, prostacyclin and by increasing removal of endothelin from the circulation. (Figure 2) Although this indicates ET-1 can stimulate either vasoconstriction or vasodilation, the overall response in vivo is sustained and powerful vasoconstriction (Rubanyi and Polokoff 1994). There is evidence that enhanced ET-1 vasoconstriction is involved in the pathology of such conditions as hypertension, heart failure, myocardial infarction, renal failure, and secondary vasospastic disorders (Ortega and de Artinano 1997).
A number of studies have investigated the role of ET-1 in glaucoma. ET-1 has been shown to decrease blood flow to the anterior optic nerve when directly applied to this region (Orgul et al 1996). It has been determined that ET-1 provokes forceful contractions of isolated ophthalmic arteries with smaller vessels expressing greater ET-1 sensitivity (Haefliger et al 1992; Polak et al 2003). Utilizing arteries dissected from gluteal fat biopsies, Buckley and colleagues (2002) identified dysfunction of the systemic vascular endothelial cell in patients with NTG by demonstrating decreased responsiveness to ET-1 stimulation. Alterations in the vascular responsiveness to ET-1 or changes in synthesis, activation, and removal of the molecule may therefore result in impaired regulation of ocular blood flow. Several studies have demonstrated increased plasma ET-1 levels in NTG patients (Sugiyama et al 1995; Kaiser et al 1995), but these results have not been reproduced in patients with high tension glaucoma (HTG) (Tezel et al 1997). Aqueous humor levels of ET-1 are reportedly elevated in HTG (Noske et al 1997) and one study demonstrated a significant elevation of plasma ET-1 in HTG when the subjects were moved from the supine to upright position (Kaiser et al 1997). To further support a role for vasospasm in endothelial dysfunction, Nicolela and colleagues (2003) reported an abnormal increase in plasma ET-1 in response to body cooling in OAG patients. This suggests a hyperactive production and/or release of ET-1

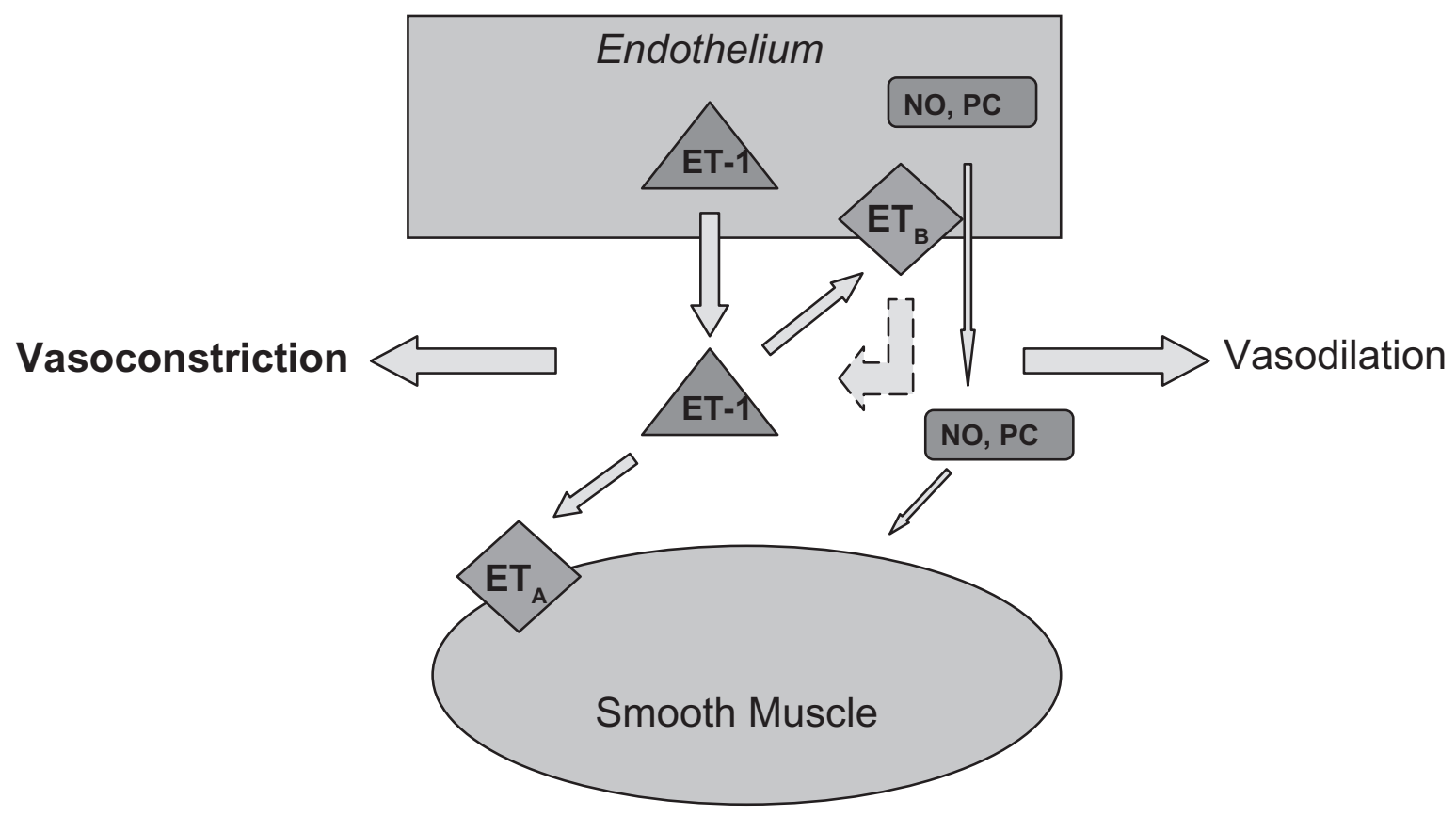

Figure 2 A schematic diagram of the known effects of endothelin-I on the endothelium and smooth muscle. The dashed line indicates an inhibitory effect. Abbreviations: $\mathrm{ET}-\mathrm{I}$, endothelin- I; NO, nitric oxide; $\mathrm{PC}$, prostacyclin; $\mathrm{ET}_{\mathrm{A}}$, endothelin-A receptor, $\mathrm{ET}_{\mathrm{B}}$, endothelin-B receptor. 
in response to vasospastic stimuli in predisposed patients (Nicolela et al 2003).

Several recent studies have shifted the focus from solely examining ET-1 expression to investigating the role of $\mathrm{ET}_{\mathrm{A}}$ and $\mathrm{ET}_{\mathrm{B}}$ receptors in ocular blood flow. In studies of porcine eyes, ET-1 increases ocular blood flow at negligible doses and reduces it at higher ones, which is thought to occur secondary to activation of $\mathrm{ET}_{\mathrm{B}}$ and $\mathrm{ET}_{\mathrm{A}}$ receptors, respectively (Yao et al 1991). This suggests that low ET-1 doses have a greater affinity for $\mathrm{ET}_{\mathrm{B}}$ receptors to cause vasodilation, but increased levels of ET-1 leads to vasoconstriction by binding to $\mathrm{ET}_{\mathrm{A}}$ receptors. Blocking $\mathrm{ET}_{\mathrm{A}}$ receptors to the exogenous administration of ET-1 in humans has been shown to reverse the observed reduction in retinal blood flow, further indicating that $\mathrm{ET}_{\mathrm{A}}$ receptors mediate the vasoconstrictive effects of ET-1 in the retina (Sugiyama et al 1995). In patients with NTG, Henry et al reported normal vasoreactivity to ET-1, but significantly decreased vasodilation in response to $\mathrm{ET}_{\mathrm{A}}$ receptor antagonism. The authors suggest this response may be due to a combination of diminished $\mathrm{ET}_{\mathrm{A}}$ receptor-mediated tone, increased $\mathrm{ET}_{\mathrm{B}}$ receptor mediated contraction, or impaired release of NO (Henry et al 2006). Correspondingly, polymorphisms of the $\mathrm{ET}_{\mathrm{A}}$ receptor have been associated with NTG (Kim et al 2006).

$\mathrm{ET}_{\mathrm{B}}$ receptor polymorphisms, however, have yet to show any significant association with systemic or ocular disease (Delaney et al 2006). The role of $\mathrm{ET}_{\mathrm{B}}$ in vascular physiology is shown to be selectively dependent on the tissue bed. It has been demonstrated in both rat and monkey models of subarachnoid hemorrhage that increased smooth muscle cell $\mathrm{ET}_{\mathrm{B}}$ receptor expression induces vasospasm of cerebral vessels (Hino et al 1996; Hansen-Schwartz et al 2003). Conversely, the function of $\mathrm{ET}_{\mathrm{B}}$ in human skin seems insignificant (Lipa et al 1999). The role of $\mathrm{ET}_{\mathrm{B}}$ in ocular hemodynamics is yet to be determined, but similar to other vascular beds in the body, it is likely influenced by the proportion of endothelial to smooth muscle cells and corresponding $\mathrm{ET}_{\mathrm{A}} / \mathrm{ET}_{\mathrm{B}}$ ratio (Delaney et al 2006).

In addition to directly reducing ocular blood flow, ET-1 increases local vascular sensitivity to other vasoconstrictive elements such as angiotensin II and catecholamines (Schmetterer 1997). Grieshaber and Flammer (2005) suggest that the elevation of ET-1 in glaucoma represents an epiphenomenon rather than a distinctive mechanism. They point to the observation of significantly elevated ET-1 levels in vasospastic and systemic diseases such as multiple sclerosis, rheumatoid arthritis, fibromyalgia, and Susac syndrome. Although a pale $\mathrm{ONH}$ is often associated with these diseases, glaucoma does not occur more frequently in these patients than in the average population. This suggests that ET-1 upregulation may be secondary to repetitive perfusion insufficiency and damage occurring not only in the $\mathrm{ONH}$, but also subclinically in multiple organs (Waldmann et al 1996; Grieshaber and Flammer 2005). Although animal models have suggested that increased levels of ET-1 by itself can lead to glaucoma via ischemia (Cioffi et al 2004), these same results have not been demonstrated in human population studies.

In summary endothelial dysfunction is likely related to glaucoma, but the exact role of mediators such as NO, NOS, $\mathrm{ET}-1$, and $\mathrm{ET}_{\mathrm{A}} / \mathrm{ET}_{\mathrm{B}}$ in $\mathrm{OAG}$ pathophysiology has yet to be fully appreciated. Endothelial dysfunction may therefore be primary or secondary to vascular diseases including atherosclerosis and vasospasm in its contribution to OAG pathology.

\section{Blood pressure changes and blood flow}

Fluctuations in IOP, blood pressure, ocular perfusion pressure, and thus blood flow are implicated in OAG. A patient with vasospastic syndrome may not be able to compensate for elevations of IOP and/or blood pressure dips, while a healthy patient can autoregulate to maintain consistent ocular perfusion. While not detailed in this review, several studies have found a modest association between OAG and hypertension (Tielsch et al 1995; Bonomi et al 2000; Mitchel 2004), while others found no significant relationships (Leske et al 1996, 2008). Choi and colleagues (2007) investigated 24-hour IOP, blood pressure, and perfusion pressure changes associated with clinically relevant visual field outcomes. The study determined that both anatomic (retinal nerve fiber layer thickness) and functional (visual field) outcome variables were significantly worse in glaucoma patients with wider circadian perfusion pressure fluctuations. The authors attributed glaucoma progression to daily repetitive ischemic insults followed by reperfusion injury in eyes through dysfunctional regulation mechanisms that could not maintain consistent perfusion pressure (Choi et al 2007). In the Thessaloniki Eye Study, patients without glaucoma having a diastolic blood pressure of $<90 \mathrm{~mm} \mathrm{Hg}$ with antihypertensive treatment was associated with increased cupping and decreased rim area of the optic disk (Topouzis et al 2006). A recent report from the European Glaucoma Prevention Study (EGPS) indicates that systemic diuretic use was associated with the development of OAG (Miglior et al 2007). This may be due to the inability of the eye to maintain consistent, adequate perfusion during pharmacologically lowered blood pressure in susceptible individuals. 
A detailed review of fluctuations in blood pressure, IOP, ocular perfusion pressure and blood flow are covered in great detail elsewhere (Werne et al 2008).

\section{Diabetes and glaucoma}

Other vascular diseases, such as diabetes, have conflicting reports about a potential role in OAG pathology (Leske et al 2007), although a significant correlation with diabetes was determined by a meta-analysis (Bonovas et al 2004). Diabetes, a disease with many vascular complications, has been reported to be related to glaucoma, however the evidence for diabetes as a contributing factor in $\mathrm{OAG}$ pathology is currently lacking. Population-based studies, such as the Baltimore eye survey, the Barbados eye study, and the Rotterdam study failed to support an association between diabetes and glaucoma. The relationship with other vascular risk factors are even less well defined, with a previous review indicating no consensus between OAG and smoking, hypercholesterolemia, or body mass index (Flammer et al 1999).

The role of other vascular diseases in glaucoma remains unclear. How each disease is related to ocular vascular regulation, or lack thereof, is uncertain. It is possible that understanding how OAG patients react differently to physiological challenges than healthy controls may reveal the differences reported in the literature. It is also possible that diabetes and hypercholesterolemia, while vascular in nature, do not directly influence ocular vascular regulation in a capacity that contributes to OAG.

\section{Clinical and therapeutic implications}

With evidence supporting vascular risk factors in glaucomatous optic neuropathy, the medical community may choose to modify the focus of OAG disease characterization and management. Certain patients with glaucoma demonstrate vascular regulatory dysfunction. Physiologic phenomenons, such as circadian variations of IOP, ocular perfusion pressure, and ocular blood flow are generating increasing evidence for their role in ocular ischemia and OAG disease processes (Werne et al 2008). Systemic medications such as antihypertensives have been shown to exacerbate OAG changes, indicating a need for heightened awareness of medication regimens in the glaucoma patient population (Netland et al 1997).

To screen for a primary vasospastic disorder, a recent review recommends practitioners include questions regarding a history of cold hands/feet, migraine or hypotension in patients (Delaney et al 2006). A thorough assessment of vascular risk factors including a history of cardiovascular disease may assist in predicting disease progression and in improving management in identified patients (Leske et al 2007).

Several vascular pharmacological targets have been identified in preliminary therapeutic trials for vascular dysfunctional regulation. Calcium channel blockers have been shown to improve outcomes in vasospastic-induced secondary ischemia in patients with subarachnoid hemorrhage (Mees et al 2007) and intractable migraine (Ng et al 2000). Authors have demonstrated calcium channel blockerinduced relief of coronary spasm following coronary artery bypass grafting (Caputo et al 1999), with one study suggesting injection of calcium blockers whenever there is reason to suspect vasospasm in arterial grafts (He et al 2000). In ocular ischemia, calcium channel antagonists can be indicated in the treatment of the ocular ischemia syndrome and amaurosis fugax (Winterkorn et al 1993; Winterkorn and Beckman 1995). Similarly, calcium channel blockers may reduce ocular vasospasm in certain glaucoma patients (Harris et al 1997; Flammer et al 1999). Several studies show that calcium channel antagonists reduce the effect of increased levels of ET-1 on ocular perfusion and improve visual field defects through induced vasodilation (Flammer et al 2001). Magnesium also reduces ET-1-induced vasospasm and although it is actively being pursued in the management of subarachnoid hemorrhage, its usefulness in glaucoma is currently unknown (Dettmann et al 1998; Mees et al 2007). Blood gas changes, including elevated $\mathrm{CO}_{2}$ breathing may also be used to test for vasospastic tendency and/or reversibility (Harris et al 1994).

The contribution of NO in the treatment of vascular dysfunctional regulation is becoming increasingly apparent. Investigations into cerebral vasospasm following cerebral vascular insults have demonstrated reduced vasospasm and ischemia-reperfusion injury with nitrate infusion (Pluta et al 2005; Jung et al 2006). The stroke literature has recently highlighted a role for initiating or continuing statin therapy in patients with vasospasm and ischemia-reperfusion injury (Endres and Laufs 2006; Trimble and Kockler 2007). These medications are thought to produce a local effect through upregulation and activation of eNOS to increase NO production (Tseng et al 2005). NO has also been shown to protect the liver and heart against reperfusion injury, with one report suggesting a role for daily dietary nitrite and nitrate therapy for optimal cardiovascular health (Bryan et al 2007). Studies concerning ocular health have demonstrated that systemic 
nitroglycerin preparations have a protective effect against optic neuropathy in glaucoma patients taking the medication for nonophthalmic reasons (Zurakowski et al 1998). Acute intravenous and oral administration of nitroglycerine lowers IOP in both glaucoma and healthy patients, with a transient increase in ocular blood flow (Wizemann and Wizemann 1980; Sinclair et al 1993). The L-arginine/NO/cyclic GMP pathway has also been implicated in the IOP decrease (Kanno et al 2000). Chronic exposure to NO may actually contribute to glaucomatous progression (Toda and Nakanishi-Toda 2007), indicating a potential role for NOS inhibition or a potential for downregulation or insensitivity. For example, inducible NOS (iNOS) is expressed only during inflammation and other pathological responses resulting in abundant NO production and eventual retinal ganglion cell loss (Toda and Nakanishi-Toda 2007). Animal trials of iNOS selective inhibition have demonstrated significantly lower retinal ganglion cell loss in treated versus untreated subjects (Neufeld et al 1999). It is therefore recommended that future efforts continue to elucidate the role of $\mathrm{NO}$ and its use in potential therapeutic interventions.

In a similar fashion, the known effect of endothelin on systemic and ocular circulation has led to a number of studies investigating potential therapeutic strategies. The pharmaceutical industry has recognized the importance of this biomolecule and an increasing number of $\mathrm{ET}_{\mathrm{A}}$ specific antagonists are undergoing trials for the management of hypertension (D'Orleans-Juste et al 2002). Preliminary studies also suggest this selective antagonism maintains endothelin's role in vascular relaxation (Takase et al 1995). Endothelin mediated pathology has been demonstrated in the ocular circulation, although application of this knowledge to disease therapy is currently limited.

\section{Conclusion}

Glaucoma is a comprehensive term for a heterogeneous disease comprising multiple etiologies. Alterations in ocular blood flow have become increasingly implicated in OAG disease pathology. The current body of literature suggests several possible mechanisms may be involved in the vascular regulatory dysfunction of OAG patients, although an inclusive appreciation from the molecular level to the clinically apparent is incomplete. Generalized vascular diseases, including endothelial dysfunction, atherosclerosis, and vasospasm may contribute to OAG disease pathophysiology. Patients suffering from vascular impairment, and therefore, faulty regulation of blood flow may be unable to compensate for physiologic fluctuations in IOP and blood pressure to maintain ocular perfusion pressures. This may result in chronic, intermittent ischemic and reperfusion damage to the $\mathrm{ONH}$, which contributes to glaucomatous optic neuropathy. Continuing research is needed to discern the significance of the vascular factors presented in this text, along with others not mentioned or unknown. Long-term multicenter clinical trials investigating the relationship between vascular dysregulation in glaucoma patients and nonclinical outcomes such as visual function and optic nerve changes are necessary.

\section{Acknowledgments}

This project was supported in part by an unrestricted research grant from Research to Prevent Blindness, New York NY. The authors report no other conflicts of interest.

\section{References}

Adams JA. 2006. ndothelium and cardiopulmonary resuscitation. Crit Care Med, 34(Suppl 12):S458-65.

Andersson PO. 1984. Vascular control in the colon and rectum. Scand J Gastroenterol Suppl, 93:65-78.

Anderson DR. 1999. Introductory comments on blood flow autoregulation in the optic nerve head and vascular risk factors in glaucoma. Surv Ophthalmol, 43(Suppl 1):S5-9.

Behrendt D, Ganz P. 2002. Endothelial function: from vascular biology to clinical applications. Am J Cardiol, 90:40L-48L.

Beltrame JF, Sasayama S, Maseri A. 1999. Racial heterogeneity in coronary artery vasomotor reactivity: differences between Japanese and Caucasian patients. J Am Coll Cardiol, 33:1442-52.

Boehm AG, Koeller AU, Pillunat LE. 2005. The effect of age on optic nerve head blood flow. Invest Ophthalmol Vis Sci, 46:1291-5.

Bogaty P, Hackett D, Davies G, et al. 1994. Vasoreactivity of the culprit lesion in unstable angina. Circulation, 90:5-11.

Bonomi L, Marchini G, Marraffa M, et al. 2000. Vascular risk factors for primary open angle glaucoma: The Egna-Neumarkt Study. Ophthalmology, 107:1287-93.

Bonovas S, Peponis V, Filioussi K. 2004. Diabetes mellitus as a risk factor for primary open-angle glaucoma: a meta-analysis. Diabet Med, 21:609-14.

Bryan NS, Calvert JW, Elrod JW, et al. 2007. Dietary nitrite supplementation protects against myocardial ischemia-reperfusion injury. PNAS, 104:19144-9.

Buckley C, Hadoke PW, Henry E. 2002. Systemic vascular endothelial cell dysfunction in normal pressure glaucoma. Br J Ophthalmol, 86:227-32.

Caputo M, Nicolini F, Franciosi G, et al. 1999. Coronary artery spasm after coronary artery bypass grafting. Eur J Cardiothorac Surg, $15: 545-8$

Choi J, Kim KH, Jeong J, et al. 2007. Circadian fluctuation of mean ocular perfusion pressure is a consistent risk factor for normal-tension glaucoma. Invest Ophthalmol Vis Sci, 48:104-11.

Cioffi GA, Wang L, Fortune B, et al. 2004. Chronic ischemia induces regional axonal damage in experimental primate optic neuropathy. Arch Ophthalmol, 122:1517-25.

Cursiefen C, Wisse M, Cursiefen S, et al. 2000. Migraine and tension headache in high-pressure and normal-pressure glaucoma. Am J Ophthalmol, 129:102-4.

Davies MJ. 1990. A macro and micro view of coronary vascular insult in ischemic heart disease. Circulation, 82(Suppl 3):II38-II46.

Davies PF, Tripathi SC. 1993. Mechanical stress mechanisms and the cell: an endothelial paradigm. Circ Res, 72:239-45. 
Davies JR, Rudd JH, Weissberg PL. 2004. Molecular and metabolic imaging of atherosclerosis. J Nucl Med, 45:1898-907.

Delaney V, Walshe TE, O'Brien C. 2006. Vasospasm in glaucoma: clinical and laboratory aspects. Optom Vis Sci, 83:406-14.

Delles C, Schmieder RE. 2004. Renal endothelial effects of antihypertensive therapy. Curr Opin Nephrol Hypertens, 13:489-93.

Dettmann ES, Luscher TF, Flammer J. 1998. Modulation of endothelin-1induced contractions by magnesium/calcium in porcine ciliary arteries. Graefes Arch Clin Ophthalmol, 236:47-51.

de Voogd S, Wolfs RC, Jansonius NM, et al. 2006. Atherosclerosis, c-reactive protein, and risk for open-angle glaucoma: the Rotterdam study. Invest Ophthalmol Vis Sci, 47:3772-6.

D'Orleans-Juste P, Labonte J, Bkaily G, et al. 2002. Function of the endothelin (B) receptor in cardiovascular physiology and pathophysiology. Pharmacol Ther, 95:221-38.

Drance SM, Douglas GR, Wijsman K. 1988. Response of blood flow to warm and cold in normal and low-tension glaucoma patients. Am J Ophthalmol, 105:35-9.

Drance S, Anderson DR, Schulzer M. 2001. Risk factors for progression of visual field abnormalities in normal-tension glaucoma. Am J Ophthalmol, 131:699-708.

Endres M, Laufs U. 2006. Discontinuation of statin treatment in stroke patients. Stroke, 37:2640-3.

Faraci FM, Heistadt DD. 1998. Regulation of the cerebral circulation: role of endothelium and potassium channels. Physiol Rev, 78:53-97.

Flammer J, Prunte C. 1991. Ocular vasospasm. I: Functional circulatory disorders in the visual system, a working hypothesis. Klin Monatsbl Augenheilkd, 198:411-12.

Flammer J. 1998. The concept of vascular dysregulation in glaucoma. In: Haefliger IO, Flammer J, (eds). Nitric oxide and endothelin in the pathogenesis of glaucoma. Philadelphia: Lippincott-Raven, pp. 14-21.

Flammer J, Orgul S. 1998. Optic nerve blood-flow abnormalities in glaucoma. Prog Retin Eye Res, 17:267-89.

Flammer J, Haefliger IO, Orgul S, et al. 1999. Vascular dysregulation: a principal risk factor for glaucomatous damage? J Glaucoma, 8:212-19.

Flammer J, Pache M, Resink T. 2001. Vasospasm, its role in the pathogenesis of diseases with particular reference to the eye. Prog Retin Eye Res, 20:319-49.

Funk RH. 1997. Blood supply of the retina. Ophthalmic Res, 29:320-5.

Galassi F, Renieri G, Sodi A, et al. 2004. Nitric oxide proxies and ocular perfusion pressure in primary open angle glaucoma. $\mathrm{Br}$ J Ophthalmol, 88:757-60.

Gaspar AZ, Gasser P, Flammer J. 1995. The influence of magnesium on visual field and peripheral vasospasm in glaucoma. Ophthalmologica, 209:11-13.

Gass A, Flammer J, Linder L, et al. 1997. Inverse correlation between endothelin-1-induced peripheral microvascular vasoconstriction and blood pressure in glaucoma patients. Graefes Arch Clin Exp Ophthalmol, 235:634-8.

Gasser P. 1989. Ocular vasospasm: a risk factor in the pathogenesis of lowtension glaucoma. Int Ophthalmol, 13:281-90.

Gasser P, Flammer J, Guthauser U, et al. 1990. Do vasospasms provoke ocular diseases? Angiography, 41:213-20.

Gasser P, Flammer J. 1990. Short-and long-term effect of nifedipine on the visual field in patients with presumed vasospasm. $J$ Int Med Res, 18:334-9.

Gasser P. 1991. Clinical syndromes with vasoconstrictor response. Wien Klin Wochenschr, 103:217-21.

Gasser P, Flammer J. 1991. Blood-cell velocity in the nailfold capillaries of patients with normal-tension and high-tension glaucoma. $\mathrm{Am} \mathrm{J}$ Ophthalmol, 111:585-8.

Gasser P. 1998. Why study vascular factors in glaucoma? Int Ophthalmol, 22:221-5.

Grieshaber MC, Flammer J. 2005. Blood flow in glaucoma. Curr Opin Ophthalmol, 16:79-83.

Gugleta K, Orgul S, Hasler PW, et al. 2003. Choroidal vascular reaction to hand-grip stress in subjects with vasospasm and its relevance in glaucoma. Invest Ophthalmol Vis Sci, 44:1573-80.
Gugleta K, Orgul S, Hasler P. 2005. Circulatory response to blood gas pertubations in vasospasm. Invest Ophthalmol Vis Sci, 46:3288-94.

Haefliger IO, Flammer J, Luscher TF. 1992. Nitric oxide and endothelin-1 are important regulators of human ophthalmic artery. Invest Ophthalmol Vis Sci, 33:2340-3.

Haggendal E, Nilsson NJ, Norback B. 1969. Aspects of the autoregulation of cerebral blood flow. Int Anesthesiol Clin, 7:353-67.

Hansen-Schwartz J, Hoel NL, Zhou M, et al. 2003. Subarachnoid hemorrhage enhances endothelin receptor expression and function in rat cerebral arteries. Neurosurgery, 52:1188-94; 1194-5.

Harris A, Sergott RC, Spaeth GL, et al. 1994. Color Doppler analysis of ocular vessel blood velocity in normal tension glaucoma. Am J Ophthalmol, 118:642-9.

Harris A, Evans DW, Cantor LB, et al. 1997. Hemodynamic and visual field function effects of oral nifedipine in patients with normal-tension glaucoma. Am J Ophthalmol, 124:296-302.

Harris A, Ciulla TA, Chung HS, et al. 1998. Regulation of retinal and optic nerve blood flow. Arch Ophthalmolol, 116:1491-5.

Harris A, Harris M, Biller J, et al. 2000. Aging affects the retrobulbar circulation differently in females and males. Arch Ophthalmol, 118:1076-80.

Harris A, Jonescu-Cuypers CP, Kagemann L, et al. 2003. Atlas of Ocular Blood Flow: Vascular anatomy, pathophysiology, and metabolism. Philadelphia: Butterworth Heinemann.

Hayreh SS, Revie IH, Edwards J. 1970. Vasogenic origin of visual field defects and optic nerve changes in glaucoma. Br J Ophthalmol, 54:46-72.

Hayreh SS. 1993. The role of age and cardiovascular disease in glaucomatous optic neuropathy. Surv Ophthalmol, 43(Suppl 1):S27-S42.

Hayreh SS. 1999. Retinal and optic nerve head ischemic disorders and atherosclerosis: role of serotonin. Prog Retin Eye Res, 18:191-221.

Hayreh SS. 2001. Blood flow in the optic nerve head and factors that may influence it. Prog Retin Eye Res, 20:595-624.

He GW, Fan KY, Chiu SW, et al. 2000. Injection of vasodilators into arterial grafts through cardiac catheter to relieve spasm. Ann Thorac Surg, 69:625-8.

Heijl A, Leske MC, Bengtsson B, et al. 2002. Early Manifest Glaucoma Trial Group. Reduction of intraocular pressure and glaucoma progression: results from the Early Manifest Glaucoma Trial. Arch Ophthalmol, 120:1268-79.

Helvaci MR, Ozcura F, Kaya H. 2007. Funduscopic examination has limited benefit for management of hypertension. Int Heart J, 48:187-94.

Henry E, Newby DE, Webb DJ, et al. 2006. Altered endothelin-1 vasoreactivity in patients with untreated normal-pressure glaucoma. Invest Ophthalmol Vis Sci, 47:2528-32.

Hino A, Tokuyama Y, Kobayashi M, et al. 1996. Increased expression of endothelin B receptor mRNA following subarachnoid hemorrhage in monkeys. J Cereb Blood Flow Metab, 16:688-97.

Hulsman CA, Vingerling JR, Hofman A, et al. 2007. Blood pressure, arterial stiffness and open angle glaucoma. The Rotterdam study. Arch Ophthalmol, 125:805-12.

Johnson PC. 1986. Autoregulation of blood flow. Circ Resc, 59:483-95.

Jokuszies A, Niederbichler A, Meyer-Marcotty M, et al. 2006. Influence of transendothelial mechanisms on microcirculation: consequences for reperfusion injury after free flap transfer. Previous, current, and future aspects. J Reconstr Microsurg, 22:513-18.

Jossi N, Anderson DR. 1983. Blockage of axonal transport in optic nerve induced by elevation of intraocular pressure: effect of arterial hypertension induced by angiotensin-I. Arch Ophthalmol, 101:94-7.

Jung KH, Chu K, Ko SY, et al. 2006. Early intravenous infusion of sodium nitrite protects brain against in vivo ischemia-reperfusion injury. Stroke, $37: 2744-50$

Kaiser HJ, Flammer J, Burckhardt D. 1993a. Silent myocardial ischemia in glaucoma patients. Ophthalmologica, 207:6-7.

Kaiser HJ, Flammer J, Graf T, et al. 1993b. Systemic blood pressure in glaucoma patients. Graefes Arch Clin Exp Ophthalmol, 231:677-80.

Kaiser HJ, Flammer J, Wenk M, et al. 1995. Endothelin-1 plasma levels in normal-tension glaucoma: abnormal response to postural changes. Graefes Arch Clin Exp Ophthalmol, 233:484-8. 
Kanno M, Araie M, Koibuchi H, et al. 2000. Effects of topical nipradilol, a beta-blocking agent with alpha-blocking and nitroglycerin-like activities, on intraocular pressure and aqueous dynamics in humans. $\mathrm{Br} \mathrm{J}$ Ophthalmol, 84:293-9.

Kim SH, Kim JY, Kim DM, et al. 2006. Investigations on the association between normal tension glaucoma and single nucleotide polymorphisms of the endothelin-1 and endothelin receptor genes. Mol Vis, 12:1016-21.

Kontos HA, Wei EP, Raper AJ, et al. 1978. Role of tissue hypoxia in local regulation of cerebral microcirculation. Am J Physiol, 234:H582-91.

Kresh JY, Armour JA. 1997. The heart as a self-regulating system: integration of homeodynamic mechanisms. Technol Health Care, 5:159-69.

Laude K, Richard V, Thuillez C. 2004. Coronary endothelial cells: a target of ischemia reperfusion and its treatment? Arch Mal Coeur Vaiss, 97:250-4.

Leske MC, Warheit-Roberts L, Wu SY. 1996. Open-angle glaucoma and ocular hypertension: The Long Island Glaucoma Case-Control Study. Ophthalmic Epidemiol, 3:85-96.

Leske MC. 2007. Open-angle glaucoma: an epidemiologic overview. Ophthalmic Epidemiol, 14:166-72.

Leske MC, Heijl A, Hyman L, et al. 2007. Predictors of long-term progression in the early manifest glaucoma trial. Ophthalmology, 11:1965-72.

Leske MC, Wu SY, Hennis A, et al. 2008. Risk factors for incident open-angle glaucoma: the Barbados Eye Studies. Ophthalmology, 115:85-93.

Leung H, Wang JJ, Rochtchina E, et al. 2003. Relationships between age, blood pressure, and retinal vessel diameters in an older population. Invest Ophthalmol Vis Sci, 44:2900-4.

Levene RZ. 1980. Low tension glaucoma: a critical review and new material. Surv Ophthalmol, 24:621-64.

Lichter PR, Musch DC, Gillespie BW, et al. 2001. Interin clinical outcome in the collaborative initial glaucoma treatment study comparing initial treatment randomized to medications or surgery. Ophthalmology, 108:1943-53.

Lipa JE, Neligan PC, Perreault TM, et al. 1999. Vasoconstriction effect of endothelin-1 in human skin: role of ETA and ETB receptors. Am J Physiol, 276:H359-67.

Liu JH, Zhang X, Kripke DF, et al. 2003. Twenty-four-hour intraocular pressure pattern associated with early glaucomatous changes. Invest Ophthalmol Vis Sci, 44:1586-90.

Luscher TF, Tanner FC, Tschudi MR, et al. 1993. Endothelial dysfunction in coronary artery disease. Ann Rev Med, 44:395-418.

Mchedlishvili G. 1981. The nature of cerebral vasospasm. Blood Vessels, 18:311-20.

McKendrick AM, Vingrys AJ, Badcock DR, et al. 2000. Visual field losses in subjects with migraine headaches. Invest Ophthalmol Vis Sci, 41:1239-47.

Mees D SM, Rinkel GJ, Feigin VL, et al. 2007. Calcium antagonists for anerysmal subarachnoid haemorrhage. Cochrane Database Syst Rev, 3:CD000277.

Miglior S, Torri V, Zeyen T, et al. 2007. Intercurrent factors associated with the development of open-angle glaucoma in the European glaucoma prevention study. Am J Ophthalmol, 2:266-75.

Mitchel P, Lee AJ, Rochtchina E, et al. 2004. Open-angle glaucoma and systemic hypertension: The Blue Mountains Eye Study. J Glaucoma, 13:319-26.

Miyazaki H, Matsuoka H, Cooke JP, et al. 1999. Endogenous nitric oxide synthase inhibitor: a novel marker of atherosclerosis. Circulation, 99:1141-6.

Napoli C, de Nigris F, Palinski W. 2001. Multiple roles of reactive oxygen species in the arterial wall. $J$ Cell Biochem, 82:674-82.

Netland PA, Weiss HS, Stewart WC, et al. 1997. Cardiovascular effects of topical carteolol hydrochloride and timolol maleate in patients with ocular hypertension and primary open-angle glaucoma. Night Study Group. Am J Ophthalmol, 123:465-77.

Neufeld AH, Sawada A, Becker B. 1999. Inhibition of nitric-oxide synthase 2 by aminoguanidine provides neuroprotection of retinal ganglion cells in a rat model of chronic glaucoma. Proc Natl Acad Sci USA, 96:9944-8.
$\mathrm{Ng}$ TM, Kohli A, Fagan SC, et al. 2000. The effect of intravenous verapamil on cerebral hemodynamics in a migraine patient with hemiplegia. Ann Pharmacother, 34:39-43.

Nicolela MT, Walman BE, Buckley AR, et al. 1996. Various glaucomatous optic nerve appearances. A color Doppler imaging study of retrobulbar circulation. Ophthalmology, 103:1670-9.

Nicolela MT, Ferrier SN, Morrison CA, et al. 2003. Effects of cold-induced vasospasm in glaucoma: the role of endothelin-1. Invest Ophthalmol Vis Sci, 44:2565-72.

Niwa Y, Yamamoto T, Harris A, et al. 2000. Relationship between the effect of carbon dioxide inhalation or nilvadipine on orbital blood flow in normal-tension glaucoma. J Glaucoma, 9:262-7.

Noske W, Hensen J, Wiederholt M. 1997. Endothelin-like immunoreactivity in aqueous humor of patients with primary open-angle glaucoma and cataract. Graefes Arch Clin Exp Ophthalmol, 235:551-2.

O’Brien E, Murphy J, Tyndall A, et al. 1991. Twenty-four-hour ambulatory blood pressure in men and women aged 17 to 80 years: the allied Irish Bank Study. J Hypertens, 9:355-60.

Oehmer S, Harazny J, Delles C, et al. 2006. Valsartan and retinal endothelial function in elderly hypertensive patients. Blood Press, 15:185-91.

Ong K, Farinelli A, Billson F, et al. 1995. Comparative study of brain magnetic resonance imaging findings in patients with low-tension glaucoma and control subjects. Ophthalmology, 02:1632-8.

Orgul S, Gaspar AZ, Hendrickson P. 1994. Comparison of the severity of normal-tension glaucoma in men and women. Ophthalmologica, 208:142-4.

Orgul S, Meyer P, Coiffi GA. 1995a. Physiology of blood flow regulation and mechanisms involved in optic nerve perfusion. J Glaucoma, 4:427-43.

Orgul S, Kaiser HJ, Flammer J, et al. 1995b. Systemic blood pressure and capillary blood-cell velocity in glaucoma patients: a preliminary study. Eur J Ophthalmol, 5:88-91.

Orgul S, Cioffi GA, Wilson DJ, et al. 1996. An endothelin-1 induced model of chronic optic nerve ischemia in the rabbit. Invest Ophthalmol Vis Sci, 37:1860-9.

Orgul S, Gugleta K, Flammer J. 1999. Physiology of perfusion as it relates to the optic nerve head. Surv Ophthalmol, 43(Suppl 1):S17-26.

Ortega MA, de Artinano AA. 1997. Highlights on endothelins: a review. Pharmacol Res, 36:339-51.

Osusky R, Rohr P, Schotzau A, et al. 2000. Nocturnal dip in the optic nerve head perfusion. Jpn J Ophthalmol, 44:128-31.

Pache M, Dubler B, Flammer J. 2003. Peripheral vasospasm and nocturnal blood pressure dipping - two distinct risk factors for glaucomatous damage? Eur J Ophthalmol, 13:260-5.

Pernow J, Bohm F, Beltran E, et al. 2003. L-arginine protects from ischemiareperfusion-induced endothelial dysfunction in humans in vivo. $J \mathrm{Appl}$ Physiol, 95:2218-22.

Pluta RM, Dejam A, Grimes G, et al. 2005. Nitrite infusions to prevent delayed cerebral vasospasm in a primate model of subarachnoid hemorrhage. JAMA, 293:1477-84.

Polak K, Luksch A, Frank B, et al. 2003. Regulation of human retinal blood flow by endothelin-1. Exp Eye Res, 76:633-40.

Polak K, Luksch A, Berisha F, et al. 2007. Altered nitric oxide system in patients with open-angle glaucoma. Arch Ophthalmol, 125:393-8.

Quigley HA, Broman AT. 2006. The number of people with glaucoma worldwide in 2010 and 2020. Br J Ophthalmol, 90:262-7.

Reid JL, Dawson D, Macrae IM. 1995. Endothelin, cerebral ischaemia and infarction. Clin Exp Hypertens, 17:399-407.

Ronkko S, Rekonen P, Kaarniranta K, et al. 2007. Phospholipase A2 in chamber angle of normal eyes and patients with primary open angle glaucoma and exfoliation glaucoma. Mol Vis, 13:408-17.

Rubanyi GM, Polokoff MA. 1994. Endothelins: molecular biology, biochemistry, pharmacology, physiology, and pathophysiology. Pharmacol Rev, 46:325-415.

Schempp H, Elstner EF. 1998. Free radicals in the pathogenesis of ocular diseases. In: Haefliger IO, Flammer J, (eds). Nitric oxide and endothelin in the pathogenesis of glaucoma. Philadelphia: Lippincott-Raven, pp. 112-35. 
Schmetterer L, Findl O, Strenn K, et al. 1997. Effects of endothelin-1 (ET-1) on ocular hemodynamics. Curr Eye Res, 16:687-92.

Siesky B, Harris A, Klaas CL, et al. 2008. Comparison of visual function and ocular hemodynamics between pre- and post-menopausal women. Eur J Ophthalmol, 18:320-3.

Sinclair AM, Hughes AD, Sever PS. 1993. Effect of nifedipine and glyceryl trinitrate on retinal blood flow in normal subjects. J Hum Hypertens, 7:399-401.

Stroman GA, Stewart WC, Golnik KC, et al. 1995. Magnetic resonance imaging in patients with low-tension glaucoma. Surv Ophthalmol, 113:168-72.

Sugiyama T, Moriya S, Oku H, et al. 1995. Association of endothelin-1 with normal tension glaucoma: clinical and fundamental studies. Surv Ophthalmol, 39(suppl 1):S49-56.

Takase H, Moreau P, Luscher TF. 1995. Endothelin receptor subtypes in small arteries. Studies with FR139317 and bosentan. Hypertension, 25:739-43

Tezel G, Kass MA, Kolker AE, et al. 1997. Plasma and aqueous humor endothelin levels in primary open-angle glaucoma. J Glaucoma, 6:83-9.

Tielsch JM, Katz J, Sommer A, et al. 1995. Hypertension, perfusion pressure, and primary open-angle glaucoma. A population-based assessment. Arch Ophthalmol, 113:216-21.

Toda N, Nakanishi-Toda M. 2007. Nitric oxide: Ocular blood flow, glaucoma, and diabetic retinopathy. Prog Retin Eye Res, 26:205-38.

Topouzis F, Coleman AL, Harris A. 2006. Association of blood pressure status with the optic disk structure in non-glaucoma subjects: the Thessaloniki eye study. Am J Ophthalmol, 142:60-7.

Trimble JL, Kockler DR. 2007. Statin treatment of cerebral vasospasm after aneurismal subarachnoid hemorrhage. Ann Pharmacother, 41:2019-23.

Tseng MY, Czosnyka M, Richards H, et al. 2005. Effects of acute treatment with pravastatin on cerebral vasospasm, autoregulation, and delayed ischemic deficits after aneurismal subarachnoid hemorrhage. Stroke, $36: 1627-32$.

Tunny TJ, Richardson KA, Clark CV. 1998. Association study of the 5' flanking regions of endothelial-nitric oxide synthase and endothelin-1 genes in familial primary open-angle glaucoma. Clin Exp Pharmacol Physiol, 25:26-9.
Tutaj M, Brown CM, Brys M, et al. 2004. Dynamic cerebral autoregulation is impaired in glaucoma. $J$ Neurol Sci, 220:49-54.

Von Graefe A. 1857. Uber die iridectomie bei glaukom und uber den glaucomatosen prozess. Von Graefe's Arch Ophthalmol, 3:456-555.

Waldmann E, Gasser P, Dubler B, et al. 1996. Silent myocardial ischemic in glaucoma and cataract patients. Graefes Arch Clin Exp Ophthalmology, 103:1014-24.

Werne A, Harris A, Moore D, et al. 2008. The circadian variations in systemic blood pressure, ocular perfusion pressure and ocular blood flow: risk factors for glaucoma? Surv Ophthalmol, In Press.

Wilson RP, Chang WJ, Sergott RC. 1997. A color Doppler analysis of nifedipine-induced posterior ocular blood flow changes in open-angle glaucoma. J Glaucoma, 6:231-6.

Winterkorn JM, Jupersmith MJ, Wirtschafter JD, et al. 1993. Brief report: treatment of vasospastic amaurosis fugax with calcium-channel blockers. N Engl J Med, 329:396-8.

Winterkorn JM, Bechman RL. 1995. Recovery from ocular ischemic syndrome after treatment with verapamil. J Neuroophthalmol, 15:209-11.

Wizemann A, Wizemann V. 1980. The use of organic nitrates to lower intraocular pressure in outpatient and surgical treatment. Klin Monatsbl Augenheilkd, 177:292-5.

Wong TY, Klein R, Klein BEK, et al. 2003. Retinal vessel diameters and their associations with age and blood pressure. Invest Ophthalmol Vis Sci, 44:4644-50

Yao K, Tschudi M, Flammer J, et al. 1991. Endothelium-dependent regulation of vascular tone of the porcine ophthalmic artery. Invest Ophthalmol Vis Sci, 32:1791-8.

Yu DY, Alder VA, Cringle SJ, et al. 1994. Vasoactivity of intraluminal and extraluminal agonists in perfused retinal arteries. Invest Ophthalmol Vis Sci, 35:4087-99.

Zurakowski D, Vorwerk CK, Gorla M, et al. 1998. Nitrate therapy may retard glaucomatous optic neuropathy, perhaps through modulation of glutamate receptors. Vision Res, 38:1489-94. 
